Production

ENGINEERING

ARCHIVES
2016, Vol. 12, No. 3, pp 14-18

ISSN 2353-5156

ISSN 2353-7779 (print version)

(online version)

Article history: $\quad$ Received: 17.08.2016

Accepted: 10.09.2016

Online: 30.09 .2016

Available online on: http://www.qpij.pl

Exist since $4^{\text {rd }}$ quarter 2013

\title{
Cost of product functions using analysis of value
}

\author{
Luminita Parv ${ }^{1}$ \\ ${ }^{1}$ TransilvaniaUniversity of Brasov, 29, Eroilor Blvd., Brasov, Romania, phone 0040740851396 , e-mail address luminita.parv@unitbv.ro
}

\begin{abstract}
The value of use is a specific notion but of a great generality that makes the product be regarded as a complex system that transforms itself in time, thus undergoing evolution. Therefore, the product is important not in itself, but for the sake of the requirements it satisfies and for the functions it provides. In the analysis of value there are connections of a technical nature that implicitly lead to connections of an economic nature. Thus, the method of the "analysis of value" will actually examine the cost of product functions, the aim of the method being the balance of functions costs on the basis of their importance for the product. Identifying the functions represents one of the important stages of the analysis of value. The difficulty in fixing the functions derives from the fact that there are not any rules clear enough for this activity, but only principles.
\end{abstract}

Key words - analysis of value, product functions, value of use

\section{Introduction}

The analysis of value $(A V)$ is a complex method of products examination; used for improving the correlation between the value of product use and cost. Symbolically, the value can be defined by the relation:

$$
A V=\frac{V I}{P}
$$

where:

$A V$-analysis of value

$V I$-value of use

$P$-price of the product

The value of use means the utility of a product and thanks to it, this can satisfy a necessity. The price expresses the value admitted by the market. For making things simpler, cost is used instead of price. The cost represents the monetary expression of expenses with production means and with the working force necessary for obtaining a product (INGALDI M., JAGUSIAKKoCIK M. 2014).

The improvement of a product can be done by the variation of value of use or of cost:

a) utility grows together with costs decrease,

b) utility grows and costs remain constant,

c) utility remains constant, but costs decrease,

d) utility grows in a higher degree than costs.

The value of use is a specific notion but of a great generality that makes the product be regarded as a complex system that transforms itself in time, thus being in evolution.

Therefore, the product is important not in itself, but for the requirements it satisfies and for the func- 
tions it provides. In the analysis of value there are connections of a technical nature that implicitly lead to connections of an economic nature. Thus, the method of the analysis of value will actually examine the cost of product functions, the aim of the method being the balance of functions costs on the basis of their importance for the product.

Identifying the functions represents one of the important stages of the analysis of value. The difficulty in fixing the functions derives from the fact that there are not any rules clear enough for this activity, but only principles.

\section{Product function description}

The function is an essential characteristic of the product in comparison with the environment and the user. It is a constituent of the value of use and it can be done by the help of a material bearer.

The functional approach of the product represents the essential characteristic of AV. According to this conception the product is a sum of elementary functions that confer on it the predicted value of use.

According to their measuring nature and possibilities, functions are divided into two groups:

- Objective Functions - measurable technical dimensions; they are objectively intercepted by the user; they are objectively perceived but not objectively determined depending on the users' preferences;

- Subjective Functions - technical dimensions are hardly measurable or immeasurable; they are not identically observed by users; they are formed on the hierarchical system according to a statistic enquiry among users, having psycho sensorial effects as a basis.

For a correct characterization of functions it is necessary for the following rules to be respected:

R1 - The description of the main function must be stated in such a way in order not to repeat the same characteristics using other words.

R2 - The correct definition of the auxiliary functions.

A function is considered auxiliary if it does not add the value of use and it conditions by its existence the performance of one or more main or base functions;
R3 - Avoiding the description in general terms;

$\mathrm{R} 4$ - Clear differentiation in comparison with the product necessity;

R5 - Strict differentiation between the function and the domain of product use;

R6 - Do not mistake the function with the technical dimension;

R7 - Do not mistake with the technical solution.

In the phase of the analysis of a new product, viewing the fixing of its performances, the technical dimensions of functions are established according to the limits fixed on the basis of the study of the real social necessities.

The technical dimensions of secondary functions are fixed on the basis of knowing the extent they condition the main ones.

Fixing the cost of every element that is a constituent of the under units, by which the product performs its functions, allows their economic dimensioning.

The management expenses can be allotted to every constituent according to some criteria or in the total cost of functions, by taking into consideration their level of importance.

Performing the examinations of the analysis of value needs:

- fixing the relative positions of functions;

- the weight of every function in the value of product use.

For this purpose it is necessary for the functions to be compared among themselves. The comparison is done on the basis of the evaluation done by the users by the help of a previously fixed score.

The points are given by the beneficiaries of the product or by a representative number of users (BORKOWSKI S., SZKLARZYK P., KLIMECKA-TATAR D. 2013) . Only the main functions are to be compared:

Viewing the ordering according to the level of importance, the following stages are to be covered:

- a matrix is to be formed on which all the main functions of the examined product are entered.

- points of importance are given to each of them, considering that by the score 2 the most important are evaluated, by 1 the ones that have the same importance and by 0 the least important ones. 
- the functions are compared between themselves, two by two, by taking into account the three possibilities of score mentioned above.

- a point is marked on the diagonal of the matrix because each function is compared to itself;

- the score is totalized vertically and the weight is calculated in percentages.

Inside $\mathrm{AV}$, the notion of production cost of the product functions is operated. The total production cost results from summing the costs necessary for the performance of every function of the product.

The production cost represents the sum of manual labour costs $\mathrm{C}_{\mathrm{man}}$, material $\mathrm{C}_{\mathrm{mat}}$ and management $\mathrm{C}_{\mathrm{reg}}$, according to the relation (2).

$$
C_{\text {prod }}=\sum_{1}^{n} c_{\text {imat }}+c_{\text {jman }}+c_{\text {kreg }}
$$

The cost does not equal the value of the product. It can grow without necessarily adding the value. In this case the economic value of the product decreases.

Inside the examinations of IV the production cost can be differently structured in comparison with the relation presented above, resulting in the sum of:

$$
C_{\text {prod }}=\sum_{1}^{n} c_{\min }+c_{s c i}+c_{s m n}
$$

where:

$\mathrm{C}_{\text {min }}$ - minimum cost of product fabrication

$\mathrm{C}_{\text {sci }}$ - extra costs due to the imperfect conception and assigning of some useless functions and characteristics.

$\mathrm{C}_{\mathrm{smn}}$ - extra costs caused by techniques and inadequate production methods, costs due to the unproductive manual labour and the machines standing by.

After the calculation of the cost of every function, its weight is fixed in the total cost of the product.

\section{Case study of the $A O R$ 170 Product}

\section{Information Collecting}

The R 170 product is used at the SLK class (sports cars -2 doors).

It is composed of:

- door design (ger. Türenzierstab R 170);
- superior and inferior console (ger. AbdeckungOben R 170; Abdeckungunten R 170);

- ashtray lid (ger.Ascherdeckel R 170 );

- change gear design (ger. Schaltkulisse R 170);

- change gear handle (ger. Schalthebel R 170).

The study went deeply into the superior console (ger. AbdeckungOben R170) AOR 170.

Type of wood used for the AOR 170 fabrication are Nut-tree root and Chest-nut tree.

Fixing the functions of the classified list

Fixing the list takes into consideration the role of this under unit at the achievement of the product value of use.

Description of functions is follow:

A - The Esthetic Function: It plays an essential role by the fact that the AO R170 "superior board cap" product is a design product.

B - Elements Assembling: It is the function by which the functional elements (buttons for different commands) are positioned and fixed.

$\mathrm{C}$ - Ensures the resistance of the habitat: For performing this function the AO R170 product undergoes some tests of "Älterungsprüfungen" plastic tractions.

D - Anticorrosive: Willing to ensure a functioning period as long as possible the AO R170 product is tested by climatic tests.

\section{Fixing the level of importance}

The level of importance of every function for the AO R170 product is fixed following the research done over the beneficiaries' requirements by comparing the functions two by two. If a function is preferred to another one, it gets 1 as a mark from the product beneficiaries, if not, 0 (zero). In case of indifference, the functions get 1 .

It is noticed that the A - Esthetic Function has the biggest weight in the value of use, so the greatest contribution to the utility of the product.

\section{Analysis and Evaluation of Existent Situation}

\section{Technical Dimensioning of Functions}

As the functions express the essential qualities of the product, they correlate to the technical parameters and with their constructive characteristics.

The technical dimensions express the performances of the analysed product. The measuring unit will be fixed for every function so that it can measure the essence of function that is what characterizes and differentiates the considered value of use. 


\section{Economic Dimensioning}

A. Fixing the cost structures of the AO R 170 product

The cost structure of a product is fixed according to the stage at which the product presents itself: con- ception, project, prototype or it is executed in series in case the analysed AO R 170 "superior board cap" product is already included in the fabrication process.

The costs that this product implies all along its technological process are pointed out in Table 1 .

Table 1.Costs Distribution on the Technological Flux of the AO R 170 Product

\begin{tabular}{|c|c|c|c|c|c|c|}
\hline \multirow{2}{*}{\multicolumn{2}{|c|}{ Cost Elements }} & \multirow{3}{*}{$\begin{array}{l}\text { TOTAL } \\
143368\end{array}$} & \multicolumn{4}{|c|}{ of which on functions } \\
\hline & & & \multirow{2}{*}{$\begin{array}{l}\text { A } \\
42868\end{array}$} & \multirow{2}{*}{$\begin{array}{l}\text { B } \\
25200\end{array}$} & \multirow{2}{*}{$\begin{array}{l}\mathrm{C} \\
32000\end{array}$} & \multirow{2}{*}{\begin{tabular}{|c|}
$\mathrm{D}$ \\
43300
\end{tabular}} \\
\hline 1. Materials & Semi-finished & & & & & \\
\hline & Tehnological & 74065 & 30070 & 20330 & 1050 & 22615 \\
\hline \multicolumn{2}{|c|}{ MATERIAL COST } & 217433 & 72938 & 45530 & 33050 & 65915 \\
\hline \multicolumn{7}{|c|}{ 2. Manual Labour } \\
\hline \multicolumn{2}{|l|}{ veneer } & 41126 & 12184 & 11630 & 9112 & 8200 \\
\hline \multicolumn{2}{|l|}{ pressing } & 48020 & 24842 & - & 23178 & - \\
\hline \multicolumn{2}{|l|}{ injecting } & 93696 & 22708 & 53125 & 17863 & - \\
\hline \multicolumn{2}{|c|}{ varnishing } & 108151 & 86435 & - & - & 21716 \\
\hline \multicolumn{2}{|l|}{ polishing } & 97662 & 20123 & 63401 & - & 14138 \\
\hline \multicolumn{2}{|l|}{ milling } & 61295 & 20524 & - & 40771 & - \\
\hline \multicolumn{2}{|l|}{ fitting } & 67217 & 20145 & 22713 & 24389 & - \\
\hline \multicolumn{2}{|c|}{ TOTAL MANUAL LABOUR } & 517167 & 206961 & 150869 & 115283 & 44054 \\
\hline \multicolumn{2}{|c|}{ TOTAL COST } & 734600 & 279899 & 196399 & 148333 & 109969 \\
\hline
\end{tabular}

Source: own study

It is noticed that the A and B functions are sub dimensioned and the $\mathrm{D}$ function is over dimensioned, therefore it is imposed the reduction of the $\mathrm{D}$ function cost.

\section{Results and discussions}

For reducing the cost of the $\mathrm{D}$ function, that is the reduction of the material and cost with the manual labour in the varnishing and polishing department we took the following measures in comparison with the measures predicted by the DPV procedure.

- In comparison with the b) measure of the "DPV" procedure because the polishing samples have not been the best, a better sample has been drawn up, finally ordering two samples of this type. Thus, $40 €$ have been invested.

- We calculated the time of improvement by infrared of the default parts that determined the same DPV time with a cost of $1,6 €$ to 200 parts. 
Parv Luminita, Cost of product functions, Vol. 12(3)/2016

Table 2. Situation Following the Improvement of the D Function Cost

\begin{tabular}{|c|c|c|c|c|c|}
\hline No. & \multirow{2}{*}{ Name } & \multicolumn{2}{|c|}{ TOTAL COST } & \multicolumn{2}{c|}{ FUNCTION COST } \\
\cline { 3 - 6 } & & Old & new & old & new \\
\hline 1 & Material Cost & $7,013 €$ & $6,19 €$ & $2,12 €$ & $1,3 €$ \\
\hline 2 & Manual Labour Total & $16,68 €$ & $15,99 €$ & $1,42 €$ & $0,736 €$ \\
\hline & TOTAL & $23,69 €$ & $22,2 €$ & $3,54 €$ & $2,056 €$ \\
\hline
\end{tabular}

Source: own study

Thus the functions weight in the total cost will present itself as follows:

Table 3. Functions Weight in Total Cost

\begin{tabular}{|c|c|c|c|c|c|}
\hline \multirow{2}{*}{ Function Code } & \multirow{2}{*}{$\begin{array}{c}\text { Function Cost } \\
\text { (ROL) }\end{array}$} & \multirow{2}{*}{$\begin{array}{c}\text { Level of impor- } \\
\text { tance } \\
n\end{array}$} & \multicolumn{3}{|c|}{ Functions weight in total cost $P=f(C t)$} \\
\hline & & & initial & $\begin{array}{c}\text { IST } \\
\text { achieved } \\
\end{array}$ & $\begin{array}{c}\text { SOLL } \\
\text { planned }\end{array}$ \\
\hline $\mathbf{A}$ & 279899 & 4 & 38 & 40,7 & 40 \\
\hline $\mathbf{B}$ & 196399 & 3 & 27 & 28,5 & 30 \\
\hline $\mathbf{C}$ & 148333 & 2 & 20 & 21,5 & 20 \\
\hline D & 63753 & 1 & 15 & 9,3 & 10 \\
\hline
\end{tabular}

Source: own study

\section{Summary and conclusions}

In the current competitive environment, innovation, quality, and costs control there are necessary elements for companies' competitiveness. However, these elements no longer represent effective factors of differentiation and advantageous positioning with regard to clients.

Today, companies urgently need to reduce conception, planning and manufacturing delays. They also need to increase their response and anticipation ability in order to improve productivity (KARDAS E. 2016, PAULiKova A. 2016).

These new challenges give prominence to the role of the company information system as strategic element which brings potential improvement of performances.

Companies will want to invest in integration tools and control data exchange in the production environment to increase reactivity.

\section{Literature}

1. Ingaldi M., JAGUSIAK-KociK M. Value Stream Improvement of Food Product, in: Food Production Improvement (red.) BORKOWSKI S., JEREB B. University of Maribor, Faculty of Logistics, Celje, 2014.

2. KARDAS E. The assessment of quality of products using selected quality instruments, Production Engineering Archives, Vol. 10, No 1. pp 5-8, ISSN 2353-5156, 2016.

3. BORKOWSKI S., SZKLARZYK P., KLIMECKATATAR D. Streams Value Referred by the Mission Factors in Production, Trade and Service Company, University of Maribor, Faculty of Logistics, Celje, 2014.

4. Pauliková A., Čekanová K., Kopas M. QFD - Support To Higher Efficiency Of Industrial Automotive Production, Production Engineering Archives, Vol. 10, No.1. pp 2124, ISSN 2353-5156, 2016. 